\title{
Campaign-Based Citizen Science for Environmental Mycology: The Science Solstice and Summer Soil-Stice Projects to Assess Drug Resistance in Air- and Soil-Borne Aspergillus fumigatus
}

\author{
Jennifer M. G. Shelton ${ }^{*}$, Matthew C. Fisher ${ }^{*}$ and Andrew C. Singer ${ }^{\dagger}$
}

Citizen science projects are often undertaken for ecological and environmental research purposes but also have great potential for use in microbiology research to track the emergence and spread of pathogens in the environment. Science Solstice and Summer Soil-stice are mycology citizen science projects aimed at collecting air and soil samples, respectively, in the United Kingdom (UK), that will be used to culture Aspergillus fumigatus fungal spores and to determine their drug resistance. $A$. fumigatus plays an important role in the environment as a decomposer of plant material, but is also a human lung pathogen. Infection with drug-resistant spores can lead to a worse clinical outcome for the patient.

On the four solstice and equinox days between June 2018 and March 2019, volunteers were asked to collect air samples from their homes and workplaces and return them to our lab in Freepost envelopes (UK only) or were reimbursed for postage if returning samples from outside of the UK. An additional round of samples was requested from UK volunteers' gardens and/or compost on the June 2019 solstice. In total, 787 volunteers returned 2,132 air samples and 509 soil samples, which grew a total of 7,991 A. fumigatus colonies. The estimated total cost of the study was $£ 2,650$, the equivalent of $£ 0.33$ per $A$. fumigatus colony grown.

Incorporating citizen science into the environmental surveillance of drug-resistant $A$. fumigatus allowed for the simultaneous collection of hundreds of environmental samples across the entire UK on the same day. The insights generated from this study would not be practical in the absence of public participation, which offers opportunities to ask scientific questions that were previously un-askable.

Keywords: mycology; antifungal resistance; epidemiology; citizen science; environmental sampling; pathogen monitoring

\section{Introduction}

Citizen science is defined as the "intentional involvement, in a non-professional capacity, of people in the scientific process, e.g., the collection... of data" (Pocock 2015) and is becoming increasingly popular for simultaneously conducting research and engaging with the public about science. Many citizen science projects in the United Kingdom (UK) rely on volunteers to monitor population levels of native insects (Gardiner 2012; Lye 2012; Wilson 2018), wildlife (Hof and Bright 2016), birds (Cannon 2005; Sparks 2017), and plants (Rich and Woodruff 1990; Pescott 2015). Citizen scientists can also report environmental incidents with potentially harmfully effects such as toxic algal blooms (Ransom Hardison 2019) or river pollution

\footnotetext{
* MRC Centre for Global Infectious Disease Analysis, Department of Infectious Disease Epidemiology, Imperial College London, London, UK + UK Centre for Ecology \& Hydrology, Wallingford, Oxfordshire, UK Corresponding author: Jennifer M. G. Shelton (j.shelton@imperial.ac.uk)
}

(Hyder 2017), and can aid surveillance of invasive species (Pocock and Evans 2014), wildlife diseases (Robinson 2010; Lawson 2012), or plant pathogens (Brown 2017). The majority of these projects asks participants to record their visual observations, either online, through an app, or via post over a prolonged period of time.

Citizen science is also being used to monitor aspects of our environment that are invisible to the naked eye and can impact human health. Some examples are air pollution, microbial diversity, pathogen spread, and antimicrobial resistance (AMR). Global project examples include The Wolbachia Project, for which students collect insects and look for evidence of Wolbachia bacteria in their guts (Bordenstein 2010); Project MERCURRI, for which bacteria collected by citizen scientists were sent to the International Space Station (ISS) to see how they grew in space (Coil 2016); and American Gut, which compared human gut bacterial diversity in participants from the United States (US), the UK, and Australia (Mcdonald 2018). Examples in the UK include Swab \& Send, an ongoing project asking citizen scientists to 
take swabs of any object or environment they choose to help identify new antibiotic compounds (www.lstmed. ac.uk/public-engagement/swab-send); and the Open Air Laboratories (OPAL) Air Survey that asked volunteers to record lichen species in their area to map atmospheric nitrogen levels across England (Tregidgo 2013).

Although the majority of citizen science microbiology projects focus on bacteria, there are several related to mycology. Kew's Lost and Found Fungi project asks volunteers to hunt for 100 mushrooms in the UK that are rare or potentially extinct (fungi.myspecies.info/content/ lost-and-found-fungi-project), the Mushroomfinder app developed by the University of Vienna records mushroom observations across Austria (www.univie.ac.at/oemykges/ pilzfinder-at/), and the Global Sourdough Project identified bacteria and yeasts in sourdough starters sent in by bakers from around the world (Reese 2020). Both Slovenia (www.invazivke.si) and the UK (www.livingashproject.org. uk) ask volunteers to monitor Ash trees for symptoms of die-back, caused by the fungal pathogen Hymenoscyphus fraxineus; the UK citizen scientists involved are asked to tag trees they believe to be resistant to the disease.

With these projects in mind, we decided that citizen science participation had the potential to enhance our planned surveillance of antifungal resistance in spores of Aspergillus fumigatus in the UK environment. A. fumigatus is a ubiquitous fungus that decomposes dead plant matter and is also a human lung pathogen. On average, we inhale hundreds of $A$. fumigatus spores a day (Kwon-Chung and Sugui 2013), some of which cause hypersensitisation and fungal asthma, or aspergillosis disease, which ranges from chronic colonisation of the airways to invasive bloodstream infections. In the UK, as many as 400,000 individuals suffer from severe asthma with fungal sensitisation (SAFS), approximately 238,000 individuals have aspergillosis lung disease, and an estimated 4,200 individuals have invasive aspergillosis (IA) (Pegorie 2017). IA has a mortality rate ranging from 30\% to $80 \%$ (Bongomin 2017), and its prevalence is increasing in the UK because of the ageing population and increasing numbers of patients who receive immunosuppressive therapies for transplant, cancer, or autoimmune conditions (Löbermann 2012). Patients that are in critical care with severe viral infections such as influenza are at high risk of IA (Schauwvlieghe 2018), and we are already witnessing examples of IA in patients that are ill with COVID19. Increasingly, aspergillosis infections are resistant to the medical antifungals (i.e., azole drugs) used to treat them despite no prior exposure of the patient to these drugs, which suggests pre-inhalation environmental acquisition of resistance by the infecting spores.

In these projects, we asked citizen scientists across the UK to collect outdoor air and soil samples in a campaign-based, single-time point manner from which $A$. fumigatus spores were cultured and will ultimately be tested for azole antifungal-resistance. A citizen science approach has not previously been employed to assess the prevalence of drug-resistant $A$. fumigatus in environmental samples. Until now, much of the focus around environmental monitoring of airborne A. fumigatus spores in the UK has been on industrial composting facilities and on potential risks to workers and nearby residents, with reports published by the Department for Environment, Food \& Rural Affairs (Defra) (Knight 2009), the Environment Agency (EA) (Environment Agency 2018) and Health \& Safety Executive (HSE) (Gilbert 2003). Further studies have collected air and/or soil samples from areas in the UK over time to assess the prevalence of azole-resistant A. fumigatus: Greater Manchester from 2009 to 2011 (Alshareef and Robson 2014; Bromley 2014), Dublin from 2014 to 2016 (Dunne 2017), South Wales from June to November 2015 (Tsitsopoulou 2018), and six sites across Southern England from May to July 2018 (Sewell 2019). These studies give valuable insight but are limited in sample number and coverage because samples were collected by the studies' authors. The citizen science methodology of this study had several objectives: 1) to achieve an increase in UK spatial sampling coverage from previous studies, 2) to trial the efficacy of the chosen sample collection methods on citizen scientists as a viable approach for mycological research, and 3) to determine whether memorable solstice sampling dates could assist in seasonal sample collections. In this paper, we demonstrate that these air- and soil-sampling citizen science projects, Science Solstice and Summer Soil-stice respectively, achieved these objectives. The main outcomes were 1) UK-wide coverage of air and soil samples at single-time point collections that exceed the geographical spread of previous studies, 2) the demonstration that citizen science approaches to sampling are valid for collection of mycological data, and 3) that the use of memorable sampling dates ensured that collection time points did not overlap and each belonged to a defined season. In this paper, we describe in detail how the citizen science projects were organized and conducted to make them repeatable for other microbiology and mycology groups who may wish to use citizen science approaches in their own research.

\section{Methods}

We asked individuals residing in the UK to collect spore samples from their local air on four dates $\left(21^{\text {st }}\right.$ June 2018 , $24^{\text {th }}$ September 2018, $21^{\text {st }}$ December 2018, and 20 $0^{\text {th }}$ March 2019) and garden soil on one date (21 $1^{\text {st }}$ June 2019). These dates were chosen because 1) as the solstice and equinox dates, they are easy to remember and make for catchy advertising; 2) they are equally spaced throughout the year, making the data useful for examining seasonal shifts in spore recovery, and allowing for sufficient time in the laboratory to process samples before the next sampling campaign.

\section{Recruitment for citizen science projects}

Recruiting sufficient numbers of participants for these projects was core to the objective of achieving greater sampling coverage than previous studies that monitored for azole-resistant $A$. fumigatus in the UK. This was achieved by advertising the projects via posters and social media. Every communication included references to the solstice and equinox sampling dates through word play in the project name and by using an image of Stonehenge, which is iconic for such celestial events. 


\section{Posters}

Printed posters (Figure 1) were displayed outside authors' offices and on noticeboards around Imperial College London (ICL) and the UK Centre for Ecology \& Hydrology (UKCEH). In addition to sampling date, project name, and an image of Stonehenge, the posters contained a brief description of the project that aimed to be understandable to non-scientists, a link to an online blog post containing further information, and the Twitter handles of the primary author and the project, which could be followed for regular updates. At the bottom of each poster was a shortened URL to a Google sign-up form (Supplemental File 1).

Online recruitment

Recruitment posts were published on the social media platforms Twitter and Facebook, as well as on several mycology websites and on The Aspergillosis Trust website (www.aspergillosistrust.org). Posts contained an image of a poster, a brief description of the project, and a link to the Google form. Twitter was chosen as a way of advertising the project and providing project updates because Tweets are visible to the public and can be shared by anyone to achieve greater visibility. Furthermore, Twitter did not require the participants to befriend or follow the authors as on other social media platforms, and project updates on Twitter avoided potentially upsetting participants by sending unsolicited emails. Emails were sent by co-authors to ICL and UKCEH mailing lists, and contained a poster, a description of the project, and a link to the Google form.

\section{Sign-up forms}

Potential participants were directed towards a Google form that requested their name and address, for postage purposes; their email address, for a reminder email, which would be sent the week before the collection dates; and mobile number, for a reminder text to be sent the evening before. In the Google form for the initial airsampling round only, participants were asked for their affiliate research institute (if any) and how they had heard of the project. Answering was optional. All communications were checked for General Data Protection Regulation (GDPR)-compliance with the new rules introduced on $25^{\text {th }}$ May 2018, and participants were informed via the Google form and via email about how their personal data would be used, stored, and kept confidential.

\section{Air-sampling packs}

Participants who filled in the Google form to take part in one or more of the four air-sampling rounds were sent an air-sampling pack containing a MicroAmp ${ }^{\mathrm{TM}}$ clear adhesive film (Applied Biosystems ${ }^{\mathrm{TM}}$, UK) cut in half (to produce two air samplers) with adhesive putty attached for securing them in place. The pack also contained a poster, a questionnaire (Supplemental File 2), simple instructions (Supplemental File 3), and a brief scientific description of the experimental aims (Supplemental File 4). On sampling day, participants were asked to attach the air samplers to outdoor ground floor windowsills at their home and workplace, exposing the sampler by peeling off the backing slip for 6 to 10 hours. If rain was forecast, participants were asked to sample on the soonest dry day afterward, as rain falling on the air samplers reduced their stickiness and therefore their ability to capture spores. They were then asked to re-cover the air samplers and return them by post, along with the completed questionnaire, in the Freepost envelope provided. The questionnaire asked the date and geographical locations of sample collection, whether they were collected from outdoor ground-floor

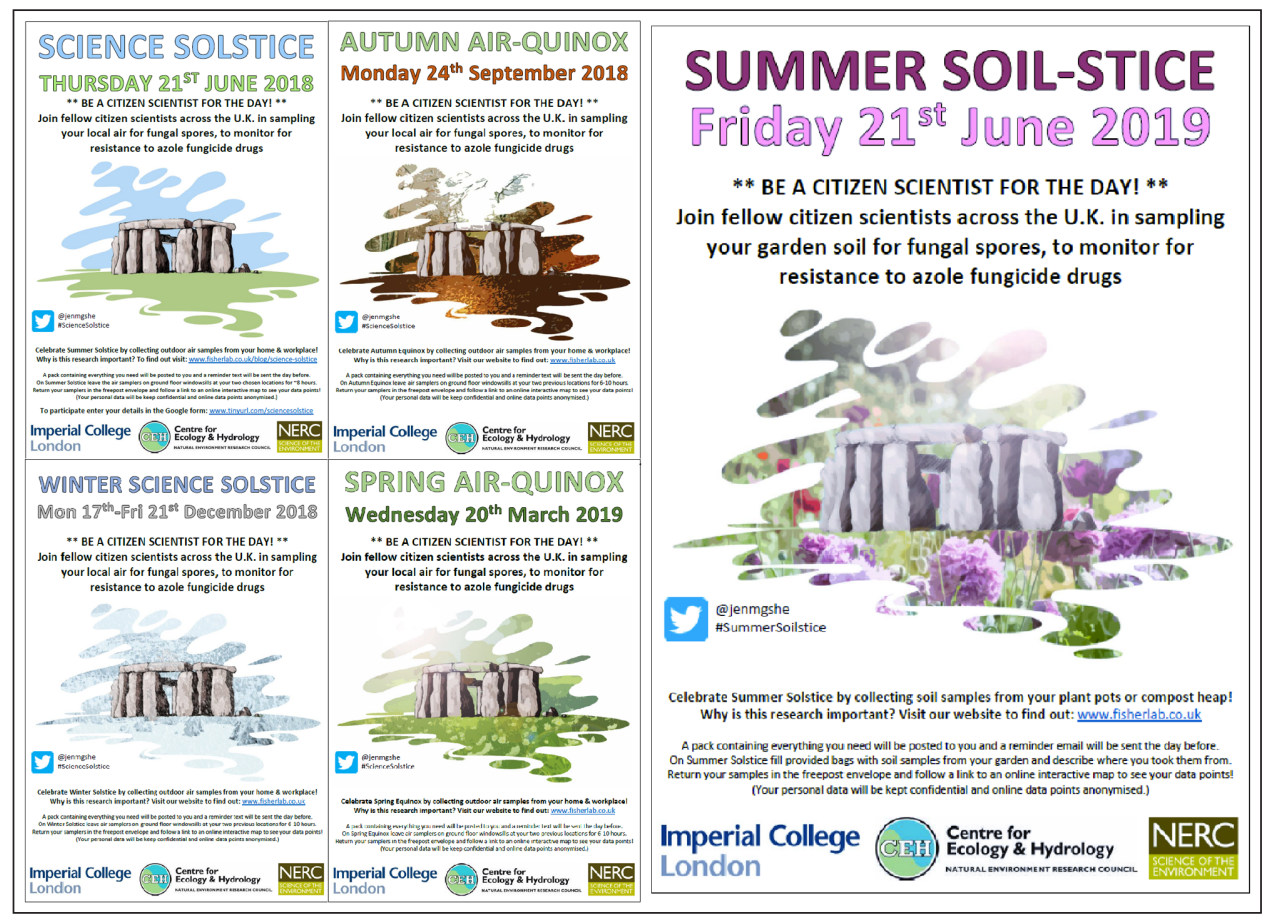

Figure 1: Posters advertising for citizen scientists to take part in United Kingdom-wide air- and soil-sampling projects were displayed around Imperial College London (ICL) and UK Centre for Ecology \& Hydrology (UKCEH) and posted on social media platforms prior to sampling dates. 
windowsills, and the participant's email (if they wished to receive project updates).

Upon receipt, A. fumigatus spores were grown into colonies directly from the air samplers onto petri dishes containing agar and antibiotics, to prevent bacterial contamination, and stored at $4^{\circ} \mathrm{C}$ in a refrigerator for further analysis. The identity of cultured colonies was confirmed as A. fumigatus by their growth at $43^{\circ} \mathrm{C}$ (A. fumigatus is one of few common fungi able to grow at this temperature), by the blue-green colour of the colonies, and by their appearance under a microscope (Figure 2).

\section{Soil-sampling packs}

The soil-sampling project Summer Soil-stice followed after the four rounds of air sampling for the Science Solstice project were completed. Participants who filled in the Google form to take part in soil sampling were sent a pack containing two plastic sachets, a wooden spatula, a poster, simple instructions (Supplemental File 5), and a brief scientific description of the experimental aims. They were asked to fill two plastic sachets with soil from their garden and complete a questionnaire (Supplemental File 6) detailing the geographical location of their garden, the location of the soils within their garden (pot or planter, border, bag of compost, bag of manure, compost heap), and a brief description of the sample (e.g., plant or bulb type in pot, brand of compost or manure, contents of compost heap). They were then asked to return the sealed sachets of soil and the questionnaire in the Freepost envelope provided. Upon receipt, $2 \mathrm{~g}$ of each soil sample was plated onto petri dishes containing agar to culture $A$. fumigatus colonies, which were then stored at $4^{\circ} \mathrm{C}$ in a refrigerator for further analysis, along with the remainder of the soils.

For the soil-sampling project, a blog post published on the UKCEH website (Supplemental File 7) explained that compost heaps and bags of compost might act as hotspots for the growth of azole-resistant $A$. fumigatus. In an effort to mitigate exposure, participants were advised to exercise caution when sampling from these locations as disturbance can lead to aerosolization of large numbers of spores. People were asked not to take part in the project if they suffer from aspergillosis, have a lung condition (chronic or acute, such as influenza), or are immunosuppressed, as these all put them at greater risk of contracting aspergillosis from inhaling a large number of spores. Participants were asked to sample from locations within their own garden only so they experienced equivalent or lesser exposures in taking part as from standard gardening activities such as potting, digging, and compost manipulation. Participants were free to opt out at any time by emailing the primary author or by not collecting samples.

\section{Citizen science engagement}

Participants were encouraged throughout the air- and soil-sampling projects to share photos of their sampling on the designated day via Twitter or email. When provided, participants were asked for their consent for this material to be used in future work and presentations by the authors. Participants were also given the option to opt out of the projects at any time by emailing the primary author or by not returning their samples. Participants were asked on the questionnaires to indicate whether they were happy to receive future project updates by email. Those who opted to receive updates were sent an email approximately 4-6 weeks after each round, when all samples had been processed. The emails thanked them for their participation, informed them of the number of samples received and the number of $A$. fumigatus colonies grown, and provided a link to an online Google map showing the location of each sample processed and the number of colonies grown from it.

On $25^{\text {th }}$ June 2018 , four days after the first air-sampling round, an email was sent to participants who provided an email address asking for feedback on the project via a different Google form (Supplemental File 8). This form

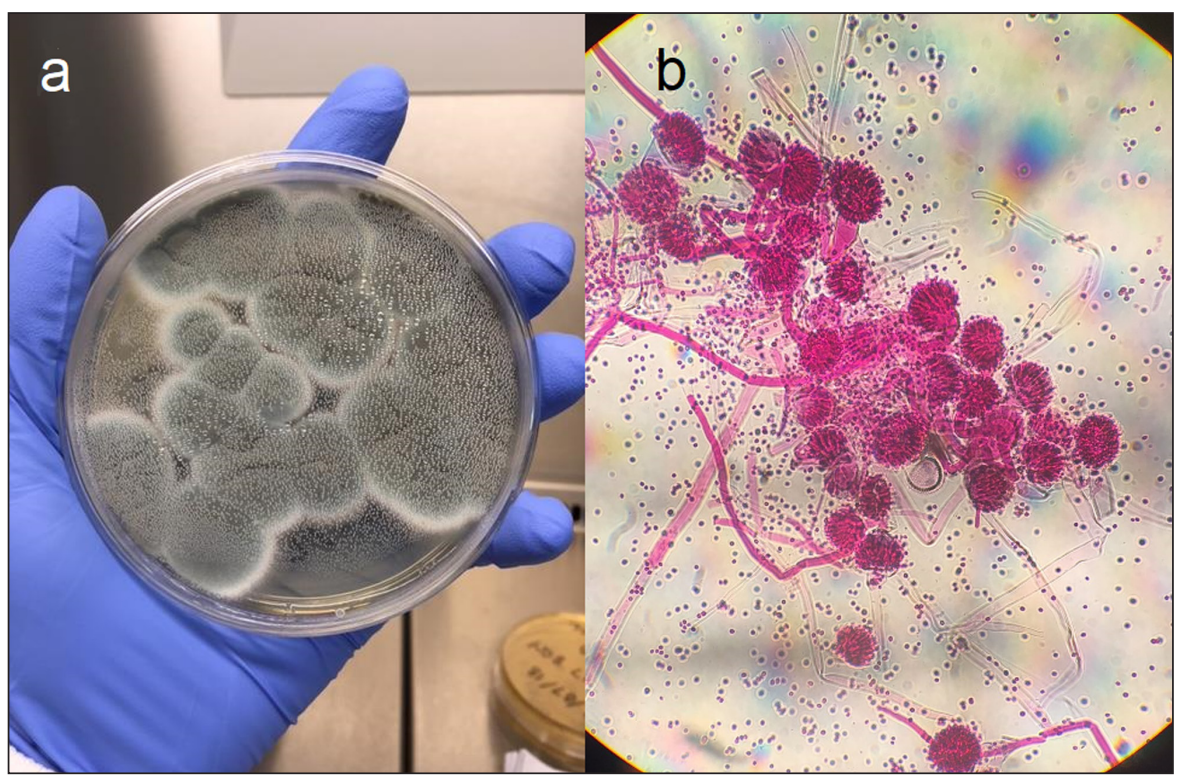

Figure 2: Colonies grown from air and soil samples were identified as A. fumigatus on the basis of their ability to grow at $43^{\circ} \mathrm{C}$, (a) their blue-green colour, and (b) their appearance under a microscope. Photos courtesy of Jennifer Shelton. 
asked whether the email and text reminders were useful and whether participants would like to take part again if the experiment was repeated. It also asked participants who did not take part their reasons for opting out, and the form had a comment box for additional feedback.

\section{Results}

Citizen science participation in the United Kingdom Across the four air-sampling rounds spanning June 2018 to March 2019, a total of 485 unique individuals residing in the UK collected one or more air samples. A total of 1,293 air-sampling packs were sent out, and 976 were returned, equating to an overall participation rate of $75 \%$. Participants collectively returned 1,896 air samples across the four dates, which were collected from all over England, Northern Ireland, Wales, and Scotland. Screenshots of the Google maps sent out to participants after the air- and soil-sampling rounds are shown alongside a UK population density map in Figure 3, which shows that the majority of samples were sent in from populous areas. Concomitantly, areas with the lowest coverage of air and soil sampling are also less densely populated. Results for

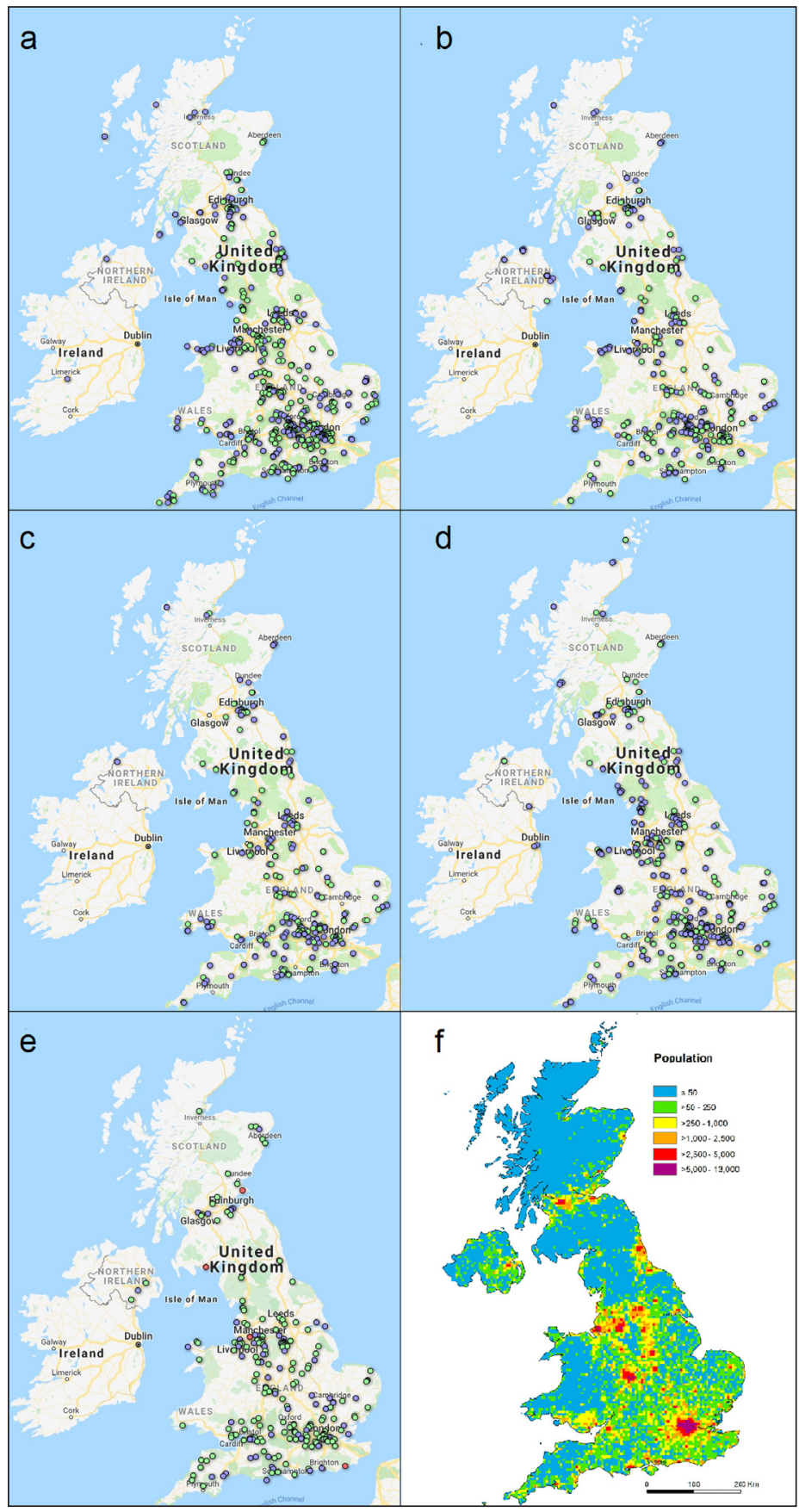

Figure 3: Google maps showing locations from which participants collected air samples on (a) $21^{\text {st }}$ June 2018 , (b) $24^{\text {th }}$ September 2018, (c) 21 $1^{\text {st }}$ December 2018, and (d) $20^{\text {th }}$ March 2019. (e) Locations that soil samples were collected from on $21^{\text {st }}$ June 2019. Blue dots indicate samplers that did not grow A. fumigatus colonies, green dots indicate samplers that did, and red dots indicate samplers that were contaminated with other fungal growth. (f) Population density map of the United Kingdom (UK) (Vieno 2015). 
individual air-sampling rounds and for the soil-sampling round are shown in Table $\mathbf{1}$.

Of the 365 participants in the first air-sampling round, $160(43 \%)$ also took part in the second round, $120(32 \%)$ in the third round, and $112(30 \%)$ took part in all four air-sampling rounds. Of the 246 participants in the soilsampling round, 43 (17\%) had already taken part in one or more of the air-sampling rounds.

\section{Citizen science participation globally}

Because of the global nature of Twitter, the first air-sampling round attracted 52 participants from 16 countries in addition to the UK. Whilst global sampling was not the intention of this study, sampling packs were sent to these participants for comparative analysis to UK samples. For the first air-sampling round, global participants sent back a total of 144 samples from Australia, Belgium, Canada, Chile, China, France, Germany, Hungary, Italy, Madagascar, New Zealand, Portugal, Spain, The Gambia, The Netherlands, and the USA. The second air-sampling round received 92 samples from 50 individuals overseas: Canada, France, Germany, New Zealand, Portugal, Spain, and the US. For the third and fourth air-sampling rounds, it was decided not to send sampling packs abroad as the Freepost return envelopes were not valid in other countries and the authors thought it unfair for participants to pay for postage. Soil sampling was open to UK participants only because of restrictions on moving soil samples between countries.

\section{Isolation of $A$. fumigatus from samples}

The 1,896 air samples collected and returned from the UK across the four air-sampling rounds grew a total of 2,366 of fungal colonies that were identified as A. fumigatus, and the 236 air samples collected globally across the first and second air-sampling rounds grew a total of $451 \mathrm{~A}$. fumigatus colonies (Table 2). The 509 soil samples grew a total of 5,174 colonies.

\section{Adherence to sampling date amongst United Kingdom samples}

The first air-sampling round had the highest adherence to sampling date (94\%), which dropped to $\sim 60 \%$ for the second and fourth air-sampling round (Table 3 ). This drop was due to the primary author's communication with participants preceding the second, third, and fourth airsampling dates to collect air samples 3 days either side of the sampling date if they were unable to participate on the sampling date itself. The decision was taken that sample number was more important than sampling date, as feedback from the first air-sampling round suggested that flexibility in sampling date would increase participa-

Table 1: Numbers of sampling packs sent out and of packs and samples returned across the four air-sampling rounds and one soil-sampling round.

\begin{tabular}{llrrrr} 
Type of sampling & Sampling date & Packs sent out & Packs returned & Return rate (\%) & Samples collected \\
\hline Air & $21^{\text {st }}$ June 2018 & 461 & 365 & 79 & 712 \\
& $24^{\text {th }}$ September 2018 & 300 & 204 & 68 & 398 \\
& $21^{\text {st }}$ December 2018 & 231 & 165 & 71 & 321 \\
& $20^{\text {th }}$ March 2019 & 301 & 242 & 80 & 465 \\
Soil & $21^{\text {st }}$ June 2019 & 334 & 246 & 74 & 509
\end{tabular}

Table 2: Numbers of samples that grew A. fumigatus colonies and of colonies cultured across the four air-sampling rounds and one soil-sampling round.

\begin{tabular}{|c|c|c|c|}
\hline Type of sampling & Sampling date & $\begin{array}{c}\text { Number of samples that } \\
\text { grew } A \text {. fumigatus } \\
\text { (\% of total) })^{\mathrm{a}}\end{array}$ & $\begin{array}{l}\text { Number of } A \text {. fumigatus } \\
\text { colonies cultured }^{\mathrm{a}}\end{array}$ \\
\hline \multirow[t]{8}{*}{ Air } & $21^{\text {st }}$ June 2018 & & \\
\hline & $U K$ & $408(57)$ & 1152 \\
\hline & global & $81(56)$ & 280 \\
\hline & $24^{\text {th }}$ September 2018 & & \\
\hline & $U K$ & $190(48)$ & 429 \\
\hline & global & $63(69)$ & 171 \\
\hline & $21^{\text {st }}$ December 2018 & $152(47)$ & 477 \\
\hline & $20^{\text {th }}$ March 2019 & $169(36)$ & 308 \\
\hline Soil & $21^{\text {st }}$ June 2019 & $327(64)$ & 5174 \\
\hline
\end{tabular}

a These numbers represent fungal isolates cultured from samples that were identified as A. fumigatus. 
Table 3: Dates that United Kingdom samples were collected for four air-sampling rounds and one soil-sampling round.

\begin{tabular}{|c|c|c|c|c|}
\hline $\begin{array}{l}\text { Type of } \\
\text { sampling }\end{array}$ & Sampling date & $\begin{array}{l}\text { Samples missing } \\
\text { date (\% of total) }\end{array}$ & $\begin{array}{l}\text { Number of samples } \\
\text { collected on intended } \\
\text { sampling date } \\
\text { (\% of total) }\end{array}$ & Range of sampling dates \\
\hline \multirow[t]{4}{*}{ Air } & $21^{\text {st }}$ June 2018 & $8(1)$ & $669(94)$ & $20^{\text {th }}$ June $-1^{\text {st }}$ July \\
\hline & $24^{\text {th }}$ September 2018 & $9(2)$ & $249(62)$ & $17^{\text {th }}$ September- $1^{\text {st }}$ October \\
\hline & $21^{\text {st }}$ December $2018^{\mathrm{a}}$ & $4(1)$ & $12(3)$ & $12^{\text {th }}$ December-19 $19^{\text {th }}$ January \\
\hline & 20 $0^{\text {th }}$ March 2019 & $5(1)$ & $287(61)$ & $13^{\text {th }}$ March-2 $-24^{\text {th }}$ April \\
\hline Soil & $21^{\text {st }}$ June 2019 & $2(0)$ & $261(51)$ & $16^{\text {th }}$ June-22 $2^{\text {nd }}$ July \\
\hline
\end{tabular}

${ }^{a}$ Because of weather conditions, and proximity to Christmas, participants for the third air-sampling round were asked to collect on any suitable day between $17^{\text {th }}$ and $21^{\text {st }}$ December, hence low adherence to sampling date.

tion. The third air-sampling round had the lowest adherence to date because it was the week before Christmas and the weather was unpredictable, so participants were encouraged to sample on any date between $17^{\text {th }}$ and $21^{\text {st }}$ December 2018 with suitable weather, which $274(85 \%)$ did. Sample date was less important for the soil sampling because it was not affected by weather conditions, so less emphasis was placed on timing.

\section{Recruitment method}

For the first air-sampling round participants were asked several optional questions on the Google sign-up form. Of the 513 individuals who completed the form, in the UK and globally, 233 (45\%) belonged to a research institute and 489 (95\%) indicated how they'd heard of the project. The research institutes that recruited the most individuals were the authors' institutes, UKCEH $(n=36)$ and ICL $(n=16)$. Individuals heard of the project on Facebook $(n=139)$, via email $(n=128)$, on Twitter $(n=103)$, through word-of-mouth $(n=97)$, and other $(n=46)$. The Tweet recruiting individuals for the first air-sampling round (\#ScienceSolstice) made 27,731 impressions and received 642 total engagements. The Tweet recruiting for subsequent air-sampling rounds (\#AutumnAirquinox, \#WinterScienceSolstice and \#SpringAirquinox) made 13,288 impressions and had 244 engagements, and the Tweet for soil sampling (\#SummerSoilstice) made 29,350 impressions and had 823 engagements.

\section{Participant feedback}

During all air- and soil-sampling rounds, participants engaged with the primary author by emailing or tweeting photos of themselves or family taking part in the sampling (Figure 4). The primary author received many messages of support by email, on Twitter and handwritten on completed questionnaires, and has been requested by several participants to talk about the citizen science projects in schools and at meetings and conferences.

After sending update emails for each sampling round, the primary author received email replies from participants expressing interest in the results, pleasure in taking part, and even disappointment or apologies that their sample(s) had not grown A. fumigatus. Leading up to, and following on from, the update emails were progress updates on Twitter that included photographs of samples being returned and the primary author in the laboratory processing samples. These Tweets were well received and maintained contact with participants who had opted to follow the primary author and/or project on Twitter without sending unsolicited emails to participants who had agreed to receive only the final update email. They also allowed interested individuals to follow the project even if they hadn't participated, and on several occasions these individuals got in touch asking to participate in future sampling rounds.

There were 118 responses to the Google feedback form, which was sent out via email after the first air-sampling round, and only 9 of those responses were from individuals who had not participated. The reasons they gave for not participating were the air sampler(s) blew away or was removed $(n=6)$, the air-sampling pack did not arrive in time $(n=1)$, and they hadn't made it to a post box yet but still intended to post $(n=2)$. Out of the 118 responders, $115(98 \%)$ found the email reminders helpful and 2 $(2 \%)$ did not receive any. Fewer responders $(n=98,85 \%)$ found the text reminder (Supplemental File 9) the evening before useful, $3(3 \%)$ did not find it useful, and 14 $(12 \%)$ did not receive it. Of the 118 responders, 115 said they would like to participate in the citizen science experiment again if it was repeated, and they provided their email address. 79 responders left additional feedback in the comment box (Supplemental File 10), which was overall very positive and encouraging.

\section{Amendments to sampling methodology}

Participants made suggestions for improvements via personal communications with the primary author and via the Google feedback form (Supplemental File 10), and amendments were made to subsequent sampling rounds. In the first air-sampling round, white sticky labels that read "LOCATION 1 (or 2) air sampler: please peel this off and retain, to re-cover air sampler after $\sim 8$ hrs." were stuck to the back of each air sampler (Figure 5a), to correspond with locations 1 and 2 on the questionnaires. It quickly became apparent on $21^{\text {st }}$ June 2018 that several individuals had removed this label instead of peeling off the backing of the air sampler. These individuals were contacted immediately to remedy this mistake, when possible, but 


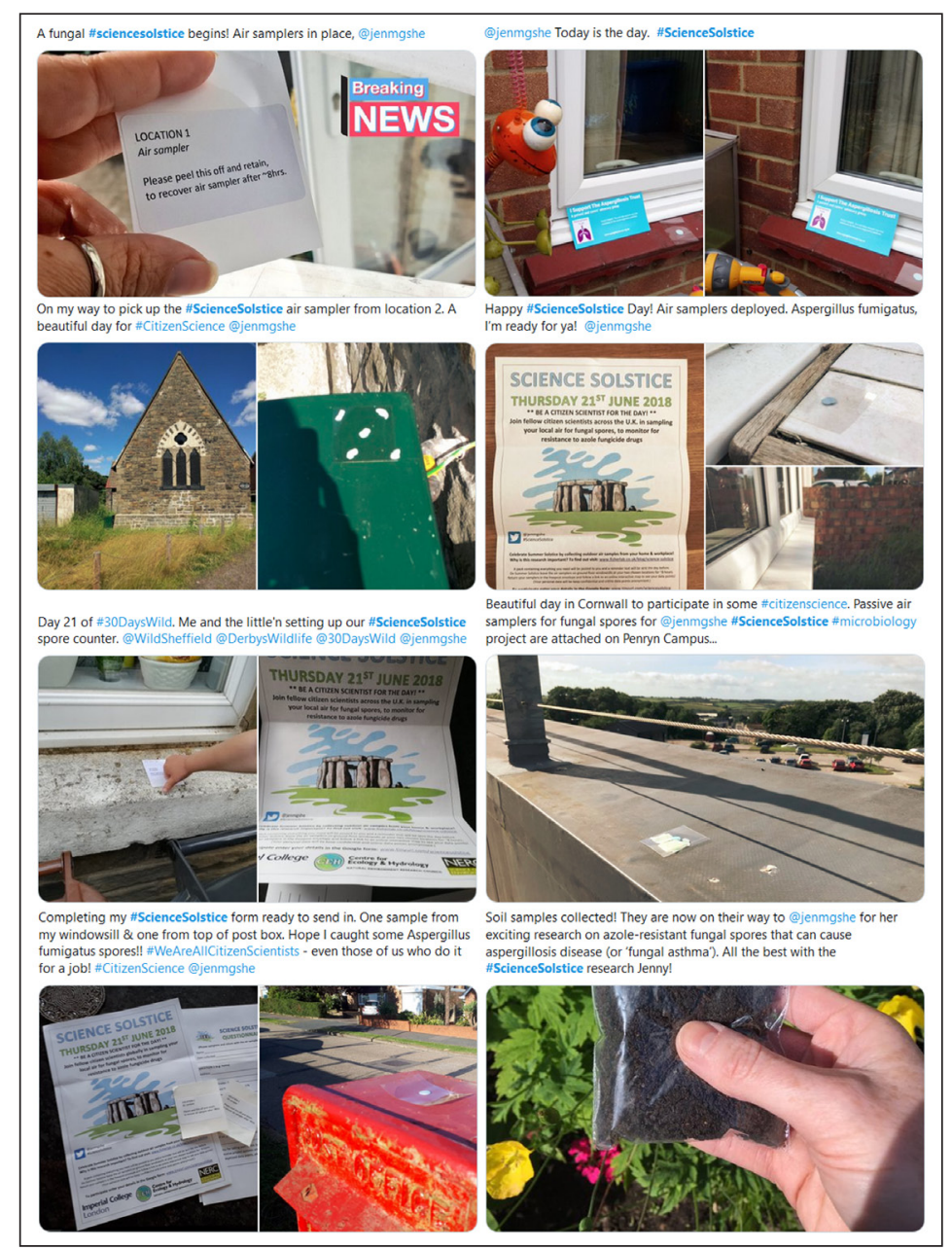

Figure 4: Several Tweets posted by participants on sampling days that show them taking part in air and soil sampling. (Permission granted by participants for these Tweets to be displayed.)
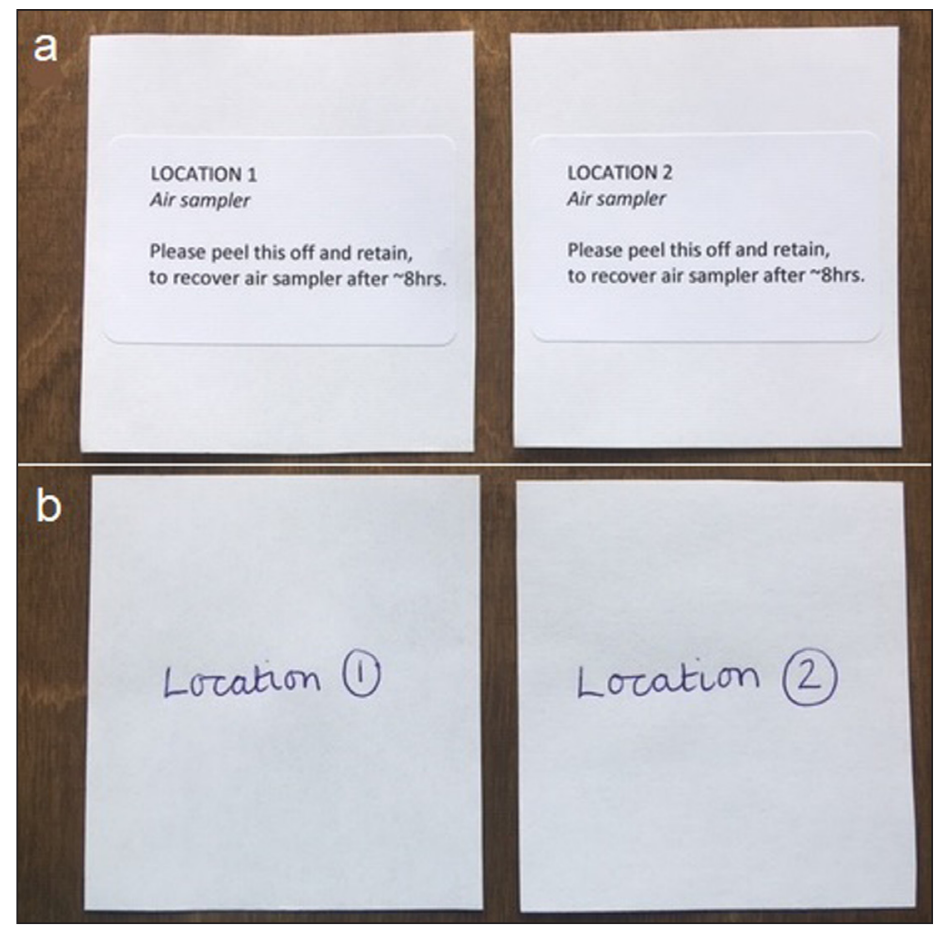

Figure 5: (a) Air samplers for first air-sampling round had sticky labels on the back with location number and basic instructions, but several participants pealed this off instead of the back of the air sampler. (b) For subsequent airsampling rounds, location number was handwritten on the back of each air sampler to avoid confusion on how to expose the air sampler. 
20 air samplers were returned that had not been exposed correctly. It is possible to tell when an air sample has not been exposed because it appears white and debris-free whereas exposed air samples are yellow, dust and debris is visible, and the sticky face and backing slip are misaligned. For subsequent air-sampling rounds, the sticky labels were not used and air samplers were instead labelled by hand either "LOCATION 1" or "LOCATION 2" (Figure 5b), and participants referred to the instruction page for exposing the air samplers.

Participants also commented during and after the first air-sampling round that their air samplers had blown away because the adhesive putty was insufficiently adhesive, so for the second air-sampling round the primary author instead attached double-sided foam tape to each air sampler. After the second air-sampling round, participants reported that the foam tape remained stuck to their windowsills and required chemical removal, so for the third and fourth air-sampling round, both adhesive putty and foam tape were provided for participants to choose between.

Several participants contacted the primary author before, during, and after the first air-sampling round to apologise for not taking part because they were occupied on the sampling date. As a result, the authors amended correspondence for subsequent air-sampling rounds to ask participants to collect samples on the sampling date whenever possible, but to collect them within 3 days either side of the sampling date if that was more convenient. A timeline of changes made to sampling methodology as a result of participant feedback is shown in Supplemental File 11.

\section{Conclusions}

This study asked citizen scientists to collect air and soil samples on five dates between June 2018 and June 2019. The primary author subsequently received a total of 2,132 air samples and 509 soil samples from 787 individuals, collected across the UK and globally. This is a substantial increase in sample coverage compared with previous studies monitoring for azole-resistant $A$. fumigatus: Alshareef and Robson (2014) collected air samples monthly over a 2-year period from one location in Manchester, Dunne (2017) collected air samples twice monthly for 2 years from 13 locations and soil samples once from 5 locations in Dublin, Tsitsopoulou (2018) collected 44 air samples and 671 soil samples over 5 months across South Wales, and Sewell (2019) collected 178 soils from 6 locations across South England. While these sampling efforts are worthwhile, none achieved UK-wide coverage of air and soil samples, which was the primary objective of this study.

The majority of participants across the five sampling rounds were resident in the UK (87\%), and samples were received from England, Northern Ireland, Scotland, and Wales. Without the involvement of citizen scientists, it would not have been possible for the authors to collect this number and distribution of air and soil samples at five single time points. The density of samples overlapped strongly with population density, and less densely populated areas, such as central Wales, were under-sampled. The sampling discrepancies do not impact the microbiology or genetics aspect of the authors' future work, but might hinder spatial analyses. Spatial coverage in low-population-density regions would need to be addressed if the study was repeated, especially as these low-density areas are likely to be farming areas where azole fungicides are sprayed, which may be driving the development of resistance in $A$. fumigatus spores.

The secondary objective of this study was to determine whether collection of air and soil samples by citizen scientists is a viable approach for mycological research, which is evidenced both by the UK-wide sample coverage and by the growth of 7,991 A. fumigatus isolates from 5 sampling dates over one year. This number far exceeds the number of isolates collected by previous surveys of air- and soilborne A. fumigatus in the UK: for example, 220 isolates from Manchester monthly air samples collected over 2 years (Alshareef and Robson 2014) and 513 isolates from South Wales air and soil samples collected over 5 months (Tsitsopoulou 2018). Both sample coverage and numbers of isolates are important for the authors' future work, which is to determine background levels of azole-resistant A. fumigatus spores across the UK and whether resistance is affected by seasonality or land use. The air- and soil-sampling methods used in this study were simple, yet the high recovery of spores from some samples shows the methods were effective, and the samples that did not grow spores show that contamination was not an issue. Feedback from participants also helped the authors to improve the sampling methods for subsequent sampling rounds. It is for these reasons that the authors conclude that passive air and soil sampling undertaken by citizen scientists is a viable way of collecting environmental samples for mycological research.

The final objective of this study addressed whether asking citizen scientists to sample on memorable solstice dates resulted in seasonal sample collections, which it did. Although adherence to sampling date dropped from 94\% for the first air-sampling round to $\sim 60 \%$ for the second and fourth and $12 \%$ for the third, the range of sampling dates did not overlap between sampling rounds so they can still be ascribed to different seasons as intended. It is important to note that this drop in adherence was the primary author's doing in asking volunteers to sample three days either side of the sampling date in the second, third, and fourth sampling rounds, if more convenient, because sample number was more important that sampling date. Whilst some citizen science projects, such as Swab \& Send at Liverpool School of Tropical Medicine (LSTM) and the Mushroomfinder app by University of Vienna, are openended and continuously accept samples or records, others define a period of time for sampling or observations. This may be to observe species when they are most abundant, in the case of the Big Butterfly Count that asks volunteers to record butterflies between mid-July and end of August (www.bigbutterflycount.org), or to coincide with well-known events such as British Science Week 2020, during which time Zooniverse asked volunteers to tag spider monkeys in thermal images of forest canopy from Central America (www.britishscienceweek.org/plan-youractivities/citizen-science/). Other projects that have used the solstice dates for sampling are Gigablitz, which asked citizen scientists in multiple countries to record biodiversity in their gardens using gigapixel imagery during the 
northern hemisphere's summer solstice 2012 (www.scs. cmu.edu/news/citizen-scientists-document-biodiversityhigh-resolution-imagery-during-summer-solstice), and the Australasian Dark Sky Alliance, which asked people to count the number of stars they saw in the Southern Cross constellation during the southern hemisphere's winter solstice 2020 (www.worldrecordlight.thinkific. com/pages/coming_soon). None of the participants in this study stated they'd not taken part because they forgot about the project, which authors believe can be attributed to the memorability of the solstice and equinox dates and the frequent television and radio broadcasts in the days beforehand. It is worth noting that the weather for the first, second, and fourth air-sampling rounds (summer, autumn, and spring, respectively) was remarkably good, which likely increased participation levels and adherence to sampling dates.

An additional aim of this study was to raise awareness of aspergillosis disease. Early diagnosis and treatment are associated with better patient outcomes (Eiff 1995), yet a survey by The Aspergillosis Trust revealed that diagnosis took between 1 to 5 years for $60 \%$ of the 128 respondents (personal comms, Sandra Hicks and Gillian Fairweather at The Aspergillosis Trust). In a survey of the scientific community on Twitter ( $n=1,267$; April 2020), only $54 \%$ replied "yes" when asked if they had heard of aspergillosis or knew what it was. This study aimed to raise awareness amongst participants by publishing blog posts and articles on institute websites and including information sheets in sampling packs about $A$. fumigatus, aspergillosis, and the relevance of widespread environmental sampling. Unfortunately, no action was taken to quantify whether this was achieved, but the authors are hopeful that participants will have greater awareness of aspergillosis having taken part in these projects.

For researchers considering using a citizen science approach, it is worth noting the high enrolment for the first air-sampling round achieved by advertising the project on social media platforms Facebook and Twitter. Because individuals "liked" and re-Tweeted the initial Tweet, which contained the poster and a link to the Google sign-up form, it reached over 27,000 people. Individuals recruited through Facebook were mostly friends and family of the primary author, those recruited by email were colleagues at ICL or UKCEH, and those who signed up through Twitter were colleagues, fellow mycologists, followers of The Aspergillosis Trust, and the general public. The return rates across the five sampling dates ranged from $68 \%$ to $80 \%$, considerably higher than the $38 \%$ return rate reported for Evolution Megalab (Worthington 2012), which asked volunteers to survey shell polymorphisms in banded snails, and the generally-accepted rate of $15 \%$ to $20 \%$ (personal comms, CEE Symposium Citizen Science, Royal Holloway University London, June 2018). Participants told the primary author that the return rate was due to the simplicity of the sampling method, the relatively small time commitment required, the enjoyment in taking part, and their interest in results.

An additional consideration is that the cost of sample collection by citizen scientists was considerably lower than if the authors had attempted to collect this number and distribution of samples themselves. Recruitment by social media platforms and email was free, stationery was provided by UKCEH and ICL, and sampling packs were sent out using ICL's franking system, so major costs were the setup and renewal of Royal Mail first-class Freepost return and purchase of lab consumables. Additionally, for the first and second air-sampling rounds, global participants were reimbursed for postage costs when possible, but global participation was discontinued in subsequent sampling rounds. An estimated $£ 1,800$ was spent on laboratory reagents and consumables, $£ 50$ on stationery, and $£ 800$ on Royal Mail postage costs, bringing the total cost of this project to $£ 2,650$. This is the equivalent of $£ 1$ per sample or $£ 0.33$ per $A$. fumigatus isolate collected across all air- and soil-sampling rounds, both from the UK and globally.

The authors' reflection on this citizen science approach for sample collection is that it has exceeded our expectations in terms of participation levels, distribution of samples, timing of sample collection, and numbers of $A$. fumigatus isolates grown for onward analysis. Involving citizen scientists has been an incredibly rewarding experience, because of their messages of support, Tweets and photos of them taking part in sampling, invitations to speak at schools and conferences, and general enthusiasm. The authors hope this study has also raised awareness of aspergillosis diseases amongst participants both in the UK and globally. This study has resulted in a collection of 7,991 A. fumigatus isolates that are to be tested for susceptibility to azole drugs to determine the prevalence and distribution of azole resistance here in the UK. The sampling techniques used were simple, inexpensive, and standardized, and could be adapted and used to monitor environmental levels of other fungal, bacterial, or viral pathogens; DNA; toxins; insects; or chemicals of interest.

\section{Supplementary Files}

The supplementary files for this article can be found as follows:

- Supplemental File 1. Google sign-up form for the first air-sampling round that was linked to by a shortened URL on the poster and in all recruitment Tweets, Facebook posts, and emails. DOI: https://doi. org/10.5334/cstp.325.s1

- Supplemental File 2. Questionnaire to be completed and returned in the Freepost envelope detailing the date air samples were collected and the exact locations where the air samplers were placed and exposed. Participants were asked to provide an email address if they wished to received future project updates. DOI: https://doi.org/10.5334/cstp.325.s2

- Supplemental File 3. Instructions explaining when and how to expose the air samplers to participate in the citizen science project Science Solstice. These instructions are for the initial air-sampling round on $21^{\text {st }}$ June 2018, and the date was amended for subsequent sampling rounds. DOI: https://doi. org/10.5334/cstp.325.s3

- Supplemental File 4. A blog post written about the citizen science project was published online when re- 
cruitment began, and a paper copy was included in each sampling pack. DOI: https://doi.org/10.5334/ cstp.325.s4

- Supplemental File 5. Instructions explaining how to collect soil samples to participate in the citizen science project Summer Soil-stice. DOI: https://doi. org/10.5334/cstp.325.s5

- Supplemental File 6. Questionnaire to be completed for the soil-sampling project and returned in the Freepost envelope, detailing the date sample collected, geographical location of the garden from which soils were collected, type of sample collected, and sample details. DOI: https://doi.org/10.5334/ cstp.325.s6

- Supplemental File 7. Blog post about soil-sampling citizen science project published on UK CEH website. DOI: https://doi.org/10.5334/cstp.325.s7

- Supplemental File 8. Google form sent out four days after the first air-sampling round asking participants for feedback on their sampling experience. DOI: https://doi.org/10.5334/cstp.325.s8

- Supplemental File 9. Texts sent the day before the first and second air-sampling rounds to participants who had provided mobile numbers reminding them to take part in sampling the next day. DOI: https:// doi.org/10.5334/cstp.325.s9

- Supplemental File 10. Participant feedback on the first air-sampling round provided in the additional comments box of the Google form sent out on $25^{\text {th }}$ June 2018. DOI: https://doi.org/10.5334/cstp.325. s10

- Supplemental File 11. Timeline of changes made to air-sampling methodology across the four air-sampling rounds as a result of participant feedback. DOI: https://doi.org/10.5334/cstp.325.s11

\section{Acknowledgements}

The authors would like to thank all the citizen scientists who took part in this study; for contributing samples and for their enthusiasm throughout. We also thank Kathy Richards for her assistance with data entry, Roseanna Collins for helping to process soil samples in the laboratory, and Joshua Jackson and Chris Edwards for their assistance with laboratory administration. Thank you to Michael Pocock for his helpful comments on an earlier version of this manuscript.

\section{Funding Information}

This work was supported by the Natural Environment Research Council (NERC; NE/L002515/1) and the UK Medical Research Council (MRC; MR/R015600/1). MCF is a CIFAR fellow.

\section{Competing Interests}

The authors have no competing interests to declare.

\section{Author Contributions}

JMGS, ACS, and MCF conceived the study and recruited participants. JMGS processed samples and communicated with participants. JMGS drafted the original manuscript, which ACS and MCF reviewed and edited.

\section{References}

Alshareef, F and Robson, GD. 2014. Prevalence, persistence, and phenotypic variation of Aspergillus fumigatus in the outdoor environment in Manchester, UK, over a 2-year period. Medical mycology, 52(4): 367-375. DOI: https://doi.org/10.1093/mmy/myu008

Bongomin, F, Gago, S, Oladele, RO and Denning, DW. 2017. Global and multi-national prevalence of fungal diseases-estimate precision. Journal of Fungi, 3(4): 57. DOI: https://doi.org/10.3390/jof3040057

Bordenstein, SR, Brothers, C, Wolfe, G, Bahr, M, Minckley, RL, Clark, ME, Wernegreen, JJ, Bordenstein, SR, Reznikoff, WS and Werren, JH. 2010. Using the Wolbachia bacterial symbiont to teach Inquiry-based science: A high school laboratory series. American Biology Teacher, 72(8): 478-483. DOI: https://doi.org/10.1525/abt.2010.72.8.3

Bromley, MJ, Van Muijlwijk, G, Fraczek, MG, Robson, G, Verweij, PE, Denning, DW and Bowyer, P. 2014. Occurrence of azole-resistant species of Aspergillus in the UK environment. Journal of Global Antimicrobial Resistance, 2(4): 276-279. DOI: https://doi. org/10.1016/j.jgar.2014.05.004

Brown, N, Bosch, F Van Den, Parnell, S and Denman, S. 2017. Integrating regulatory surveys and citizen science to map outbreaks of forest diseases: Acute oak decline in England and Wales. Proceedings of the Royal Society B, 284(1859): 1-7. DOI: https://doi. org/10.1098/rspb.2017.0547

Cannon, AR, Chamberlain, DE, Toms, MP, Hatchwell, BJ and Gaston, KJ. 2005. Trends in the use of private gardens by wild birds in Great Britain 1995-2002. Journal of Applied Ecology, 42(4): 659-671. DOI: https:// doi.org/10.1111/j.1365-2664.2005.01050.x

Coil, DA, Neches, RY, Lang, JM, Brown, WE, Severance, M, Cavalier, D and Eisen, JA. 2016. Growth of 48 built environment bacterial isolates on board the International Space Station (ISS). PeerJ, 4(e1842): 1-11. DOI: https://doi.org/10.7717/peerj.1842

Dunne, K, Hagen, F, Pomeroy, N, Meis, JF and Rogers, TR. 2017. Intercountry transfer of triazole-resistant Aspergillus fumigatus on Plant Bulbs. Clinical Infectious Diseases, 65(1): 147-149. DOI: https://doi. org/10.1093/cid/cix257

Eiff, M, Roos, N, Shulten, R, Hesse, M, Zuhlsdorf, $\mathbf{M}$ and van de Loo, J. 1995. Pulmonary aspergillosis: Early diagnosis improves survival. Respiration, 62(6): 341-347. DOI: https://doi. org/10.1159/000196477

Environment Agency. 2018. M9: Environmental monitoring of bioaerosols at regulated facilities. July 2018. Available at: https://assets.publishing.service.gov.uk/ government/uploads/system/uploads/attachment_ data/file/730226/M9_Environmental_monitoring_of_bioaerosols_at_regulated_facilities.pdf. [Last accessed 2 September 2020].

Gardiner, MM, Allee, LL, Brown, PMJ, Losey, JE, Roy, HE and Smyth, RR. 2012. Lessons from lady beetles: Accuracy of monitoring data from US and UK citizen science programs. Frontiers in Ecology, 10(9): 471-476. DOI: https://doi.org/10.1890/110185 
Gilbert, EJ, Adrian, K, Karnon, JD, Swan, JR and Crook, B. 2003. Occupational and environmental exposure to bioaerosols from composts and potential health effects-A critical review of published data. Available at: https://www.hse.gov.uk/research/rrpdf/rr130.pdf. [Last accessed 2 September 2020].

Hof, AR and Bright, PW. 2016. Quantifying the long-term decline of the West European hedgehog in England by subsampling citizen-science datasets. European Journal of Wildlife Research, 62: 407-413. DOI: https://doi. org/10.1007/s10344-016-1013-1

Hyder, K, Wright, S, Kirby, M and Brant, J. 2017. The role of citizen science in monitoring small-scale pollution events. Marine Pollution Bulletin, 120(1-2): 51-57. DOI: https://doi.org/10.1016/j.marpolbul.2017.04.038

Knight, A, Kumarswami, N, Lamarre, B, Lipscombe, RP, Robinson, RA and Williams, M. 2009. Rapid and responsive monitoring network for bioaerosol emissions: final report, (March 2009). Available at: http:// eprintspublications.npl.co.uk/4689/. [Last accessed 2 September 2020].

Kwon-Chung, KJ and Sugui, JA. 2013. Aspergillus fumigatus-What makes the species a ubiquitous human fungal pathogen? PLoS Pathogens, 9(12): 1-4. DOI: https://doi.org/10.1371/journal.ppat.1003743

Lawson, B, Lachish, S, Colvile, KM, Durrant, C, Peck, KM, Toms, MP, Sheldon, BC and Cunningham, AA. 2012. Emergence of a novel avian pox disease in British tit species. PLOS ONE, 7(11): 1-13. DOI: https://doi. org/10.1371/journal.pone.0040176

Löbermann, M, Boršo, D, Hilgendorf, I, Fritzsche, C, Zettl, UK and Reisinger, EC. 2012. Immunization in the adult immunocompromised host. Autoimmunity Reviews, 11(3): 212-218. DOI: https://doi. org/10.1016/j.autrev.2011.05.015

Lye, GC, Osborne, JL, Park, KJ and Goulson, D. 2012. Using citizen science to monitor Bombus populations in the UK: nesting ecology and relative abundance in the urban environment. Journal of Insect Conservation, 16: 697-707. DOI: https://doi.org/10.1007/s10841011-9450-3

Mcdonald, D, Hyde, E, Debelius, JW, Morton, JT, Gonzalez, A, Ackermann, G, Aksenov, AA, Behsaz, B, Brennan, C, Chen, Y and Kosciolek, T. 2018. American gut: an open platform for citizen science microbiome research. mSystems, 3(3): 1-28. DOI: https://doi.org/10.1128/mSystems.00031-18

Pegorie, M, Denning, DW and Welfare, W. 2017. Estimating the burden of invasive and serious fungal disease in the United Kingdom. Journal of Infection, 74(1): 60-71. DOI: https://doi.org/10.1016/j.jinf.2016.10.005

Pescott, OL, Walker, KJ, Pocock, MJO, Jitlal, M, Outhwaite, CL, Cheffings, CM, Harris, F and Roy, DB. 2015. Ecological monitoring with citizen science: The design and implementation of schemes for recording plants in Britain and Ireland. Biological Journal of the Linnean Society, 115(3): 505-521. DOI: https://doi. org/10.1111/bij.12581

Pocock, MJO and Evans, DM. 2014. The success of the horse-chestnut leaf-miner, Cameraria ohridella, in the UK revealed with hypothesis-led citizen science. PLOS
ONE, 9(1): 1-9. DOI: https://doi.org/10.1371/journal. pone.0086226

Pocock, MJO, Roy, HE, Preston, CD and Roy, DB. 2015. The Biological Records Centre: A pioneer of citizen science. Biological Journal of the Linnean Society, 115(3): 475-493. DOI: https://doi.org/10.1111/bij.12548

Ransom Hardison, D, Holland, WC, Currier, RD, Kirkpatrick, B, Stumpf, R, Fanara, T, Burris, D, Reich, A, Kirkpatrick, GJ and Wayne Litaker, R. 2019. Habscope: A tool for use by citizen scientists to facilitate early warning of respiratory irritation caused by toxic blooms of Karenia brevis. PLOS ONE, 14(6): 1-17. DOI: https://doi.org/10.1371/journal. pone.0218489

Reese, AT, Madden, AA, Joossens, M, Lacaze, G and Dunn, RR. 2020. Influences of Ingredients and Bakers on the Bacteria and Fungi in Sourdough Starters and Bread. mSphere, 5(1): 1-15. DOI: https://doi. org/10.1128/mSphere.00950-19

Rich, TGC and Woodruff, ER. 1990. BSBI monitoring scheme 1987-1988. Chief Scientist's Directorate Report. Available at: http://archive.bsbi.org.uk/BSBI Monitoring_scheme_1987-1988.pdf. [Last accessed $\overline{2}$ September 2020].

Robinson, RA, Lawson, B, Toms, MP, Peck, KM, Kirkwood, JK, Clatworthy, IR, Evans, AD, Hughes, LA, Hutchinson, OC, Shinto, K, Pennycott, TW, Perkins, MW, Rowley, PS, Simpson, VR, Tyler, KM and Cunningham, AA. 2010. Emerging infectious disease leads to rapid population declines of common British birds. PLOS ONE, 5(8): 1-12. DOI: https://doi. org/10.1371/journal.pone.0012215

Schauwvlieghe, AFAD, Rijnders, BJA, Philips, N, Verwijs, R, Vanderbeke, L, Van Tienen, C, Lagrou, PK, Verweij, PPE, Van De Veerdonk, FL, Gommers, PD, Wauters, PJ, et al. 2018. Invasive aspergillosis in patients admitted to the intensive care unit with severe influenza: a retrospective cohort study. The Lancet Respiratory, 6(10): 782-792. DOI: https://doi. org/10.1016/S2213-2600(18)30274-1

Sewell, TR, Zhang, Y, Brackin, AP, Shelton, JMG, Rhodes, J and Fisher, MC. 2019. Elevated prevalence of azole-resistant Aspergillus fumigatus in urban versus rural environments in the United Kingdom. Antimicrobial Agents and Chemotherapy, 63(9): 1-8. DOI: https://doi.org/10.1128/AAC.00548-19

Sparks, TH, Atkinson, S, Lewthwaite, K, Dhap, R and Moran, NJ. 2017. Can bird abundance declines be detected by citizen science programmes? A case study using common cuckoo Cuculus canorus. Avian Biology Research, 10(4): 241-245. DOI: https://doi.org/10.318 4/175815617X15036738758862

Tregidgo, DJ, West, SE and Ashmore, MR. 2013. Can citizen science produce good science? Testing the OPAL Air Survey methodology, using lichens as indicators of nitrogenous pollution. Environmental Pollution, 182: 448-451. DOI: https://doi.org/10.1016/j. envpol.2013.03.034

Tsitsopoulou, A, Posso, R, Vale, L, Bebb, S, Johnson, E and White, PL. 2018. Determination of the prevalence of triazole resistance in environmental Aspergil- 
lus fumigatus strains isolated in South Wales, UK. Frontiers in Microbiology, 9(1395): 1-8. DOI: https://doi. org/10.3389/fmicb.2018.01395

Vieno, M, Heal, MR, Williams, ML, Carnell, EJ, Nemitz, E, Stedman, JR and Reis, S. 2015. Sensitivities of UK PM2.5 concentrations to emissions reductions. Atmospheric Chemistry and Physics, 15: 20881-20910. DOI: https://doi.org/10.5194/acp-16-265-2016

Wilson, JF, Baker, D, Cheney, J, Cook, M, Ellis, M, Freestone, R, Gardner, D, Geen, G, Hemming, R, Hodgers, D, Howarth, S, Jupp, A, Lowe, N, Orridge, S, Shaw, M, Smith, B, Turner, A and
Young, H. 2018. A role for artificial night-time lighting in long-term changes in populations of 100 widespread macro-moths in UK and Ireland: a citizenscience study. Journal of Insect Conservation, 22(2): 189-196. DOI: https://doi.org/10.1007/s10841-0180052-1

Worthington, JP, Silvertown, J, Cook, L, Cameron, R, Dodd, M, Greenwood, RM, Mcconway, K and Skelton, P. 2012. Evolution MegaLab: A case study in citizen science methods. Methods in Ecology and Evolution, 3(2): 303-309. DOI: https://doi.org/10.1111/ j.2041-210X.2011.00164.x

\footnotetext{
How to cite this article: Shelton, JMG, Fisher, MC and Singer, AC. 2020. Campaign-based Citizen Science for Environmenta Mycology: The Science Solstice and Summer Soil-stice Projects to Assess Drug Resistance in Air- and Soil-borne Aspergillus fumigatus. Citizen Science: Theory and Practice, 5(1): 20, pp. 1-13. DOI: https://doi.org/10.5334/cstp.325
}

Submitted: 09 April $2020 \quad$ Accepted: 23 August $2020 \quad$ Published: 18 September 2020

Copyright: ( 2020 The Author(s). This is an open-access article distributed under the terms of the Creative Commons Attribution 4.0 International License (CC-BY 4.0), which permits unrestricted use, distribution, and reproduction in any medium, provided the original author and source are credited. See https://creativecommons.org/licenses/by/4.0/. 